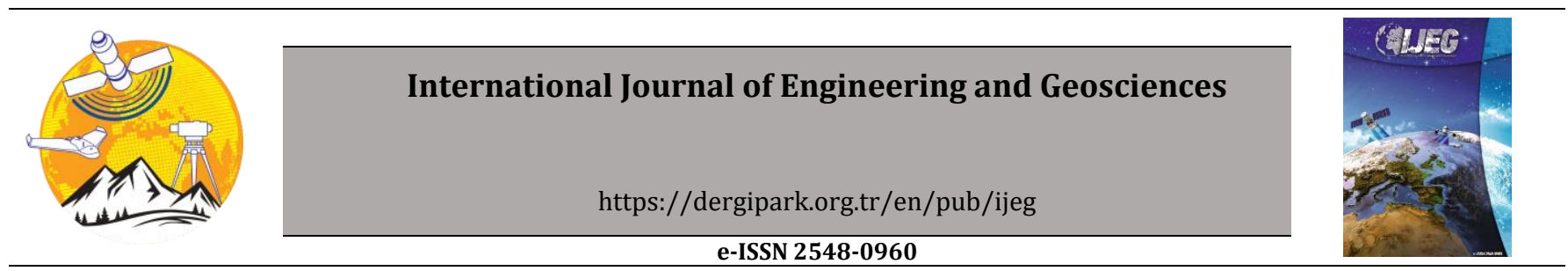

\title{
Investigation of Temporal Baseline Effect on DEMs Derived From COSMO Sky-Med Data
}

\author{
Ahmet Tarık Torun*1 ${ }^{(D)}$, Osman Orhan ${ }^{2}(\mathbb{D}$ \\ ${ }^{1}$ Aksaray University, Faculty of Engineering, Geomatics Department, Aksaray, Turkey \\ ${ }^{2}$ Mersin University, Institute of Science and Technology, Department of Remote Sensing and GIS, Mersin, Turkey
}

\author{
Keywords \\ InSAR \\ DEM \\ Baseline \\ COSMO Sky-Med
}

\begin{abstract}
Digital elevation models (DEM) are indispensable elements of sensitive earth science studies. It is important the production and usage of DEMs. The science of remote sensing offers scientists an important source of data on this subject. Radar data, which is an active remote sensing system, has an important capacity in this regard. DEM production using InSAR data has been widely used in the literature in the last decade. The temporal baseline parameter, which is an important factor in data generation from InSAR pairs, also affects the final products. In this study, it is aimed to examine the usability of these data by producing short (4days), medium (84 days) and long (440 days) baseline DEMs using InSAR pairs of COSMO Sky-Med satellite. At the same time, photogrammetric DEMs were produced with unmanned aerial vehicles (UAV) in selected pilot areas. The DEMs produced were evaluated in 4 land surface types, namely plain-bare, agricultural, urban and rugged area. In addition, by performing statistical analyzes such as RMSE, MAE, the accuracy of the produced DEMs compared to the DEMs produced with UAV was examined. The results showed that short and medium baseline data give more accurate results than long baseline InSAR pairs. Increasing the temporal baseline, increases the amount of error in the DEMs produced. Also, the effect of land surface types on the produced DEMs was revealed in the results of the study.
\end{abstract}

\section{INTRODUCTION}

The concept of the "Terrain Model" depicted as a numerical representation of the topographic surface, was first defined by Miller and Laflamme (1958). In the following years, several terms related to the representation of the topographic surface have been defined (Szypuła 2017). Among many terms, it is the digital elevation model (DEM) that is the most common and accepted in geomorphometric and GIS terminology. DEM is a shape that helps us to describe the earth mathematically, with a series of height measurements at regular/irregular intervals to best show the surface in 3D projection. In general, DEM is divided into two categories: a digital terrain model (DTM) that is free from trees, buildings and all kinds of objects, and a digital surface model (DSM) that reflects all man-made and natural objects (Martha et al. 2010).
DEMs are considered useful in many geospatial studies and applications, natural disasters (Hengl and Evans, 2009; Orhan et al. 2020a), archeology (Hageman et al. 2000), glacier and glacier analysis (Bishop et al. 2001), hydrology (Yang et al., 2015), plant cover research, urban studies, geomorphology and topography (Erasmi et al. 2014; Pope et al. 2007). Therefore, DEMs that provide information about the topography surface are essential for several different studies that are often of interest to geomorphologists as a starting point for further analysis (Güvenç, 2020). Several different techniques such as stereo satellite images, Interferometric SAR (InSAR), Global Navigation Satellite System (GNSS) measurements, topographic maps, contour lines, photogrammetry techniques, and laser scanning are used in the creation of the digital elevation model (Algancl et al. 2018; Peralvo and Maidment 2004). 
Interferometric SAR (InSAR) has been developed as the most sufficient technologies to generate DEM with better resolution and high accuracy due to its allweather, all-day characteristics, and the automatic highefficiency processing methods (Zebker and Goldstein, 1986; Bamler and Hartl, 1998; Gao et al., 2017; Karabörk et al.2021). The InSAR technique is based on the principle of converting phase information obtained from a complex interferogram into elevation data. Both amplitude and phase information of microwave energy are measured in SAR systems. While the amplitude information depends on the electrical properties such as humidity, chemical substance content and geometric properties such as surface roughness, texture, the phase information depends on the distance between the satellite platform and the earth surface, like LiDAR and GNSS systems (Erten et al. 2018).

Space-based techniques such as InSAR are highly preferred in DEM production. Before 2007, only highresolution stereo optical images were used in the production of high-resolution space-based DEMs (Sefercik et al. 2020). However, with the launched of high-resolution SAR satellites such as COSMO Sky-Med (COnstellation of small Satellites for Mediterranean basin Observation) after 2007, it has enabled the production of high-resolution DEMs under all weather conditions. The COSMO-SkyMed system, which is the unique constellation of four X-band radar satellites for Earth Observation, offers high-resolution SAR data (1m for Spotlight mode) for DEM generation. However, due to the re-pass monostatic imaging geometry, the performance of the generated DEMs was limited (Sefercik et al. 2020). The change in the earth's surface observed with the SAR images acquired at different dates causes a decrease in the coherent between the two SAR imaging systems. So, this situation prevents obtaining reliable phase data in the generation of elevation data. Therefore, the time difference between the SAR images is the main source of error in the produced DEM, and it has caused the production of DEM with low accuracy, especially in regions such as agricultural land where the temporal change is fast on the topography (Erten et al. 2018). In order to minimize limitations and increase the accuracy of acquired DEMs, COSMO Sky-med satellite works with the tandem-like interferometry system (within a 24-hour delay).

In the literature, there is a lack of information about the effect of different temporal baselines of SAR images on the DEMS derived from COSMO Sky-Med data. In this context, it is aimed to evaluate the accuracy of DEMs produced by using three COSMO Sky-med image pairs with different baselines (4-84-440 days) over the various types of surfaces such as plain-bare, rugged, agriculture and urban. UAV was used as base data in to assess the accuracy of DEM derived from COSMO Sky-Med data.

\section{STUDY AREA AND MATERIALS}

\subsection{Study Area}

Karapınar is a district located approximately 100 $\mathrm{km}$ east of Konya and is generally built on plains. Although traditional dry farming is practiced in the region, it has caused the emergence of karstic surface shapes due to irrigated agriculture and the geological structure of the region since the early 2000s (Orhan et al. 2020a). Sinkhole formations, which are caused by the misuse of groundwater in the region and continue to emerge day by day, threaten the people of the region (Orhan et al. 2020b). The main factor in choosing the study area is the coexistence of different land features in the region. Pilot areas with 4 different land surface types (plain-bare, agricultural, urban, rugged) determined in the study area were used in this study. Figure 1 provides the general boundaries of the study area and the selected pilot areas.

\subsection{Materials}

SAR images of the COSMO Sky-Med sensor were used in the study. COSMO Sky-Med, is a system that detects in $\mathrm{X}$ band and consists of 4 constellations, conceived by ASI (Agenzia Spaziale Italiana). The system is capable of observing in 3 imaging modes as spotlight, stripmap and scansar. The system can operate with single, double or full polarization. The revisit period of the system can be up to 1 day (Covello et al., 2010). In this study, 3 InSAR pairs, obtained with COSMO Sky-Med sensor, were used. InSAR pairs were created considering the temporal baselines. While selecting the InSAR pairs for DEM generation, care has been taken to ensure that other properties (polarization, orbital pass etc.) are the same, except for the baseline. Temporal baselines of selected InSAR pairs are 4 days, 84 days and 440 days, respectively. Technical information of the InSAR pairs used is presented in Table 1.

In addition to the InSAR data, photogrammetric flights were carried out using UAVS to control the produced DEMs on 15th of March 2016. In the study, photographs were taken using a DJI Phantom 4 model UAV at flight height of $100 \mathrm{~m}$, with overlap ratio of $80 \%$. Ground control points have been established on the land surface to be used in evaluating the photographs. GCPs are designed in size that can be selected from photographs. In addition, red and white colors are used to distinguish it from photographs. The coordinates of GCPs were determined by precise GNSS measurements using with real time kinematic (RTK) method. The UAV and GCP used in the study are shown in Figure 2.

Table 1. COSMO Sky-med image specifications

\begin{tabular}{cccc}
\hline & InSAR Pair 1 & InSAR Pair 2 & InSAR Pair 3 \\
\hline $\begin{array}{c}\text { Acquisition } \\
\text { Date }\end{array}$ & 11.03 .2016 & 11.03 .2016 & 11.03 .2016 \\
\hline $\begin{array}{c}\text { Orbit Pass } \\
\text { Polarization }\end{array}$ & & $\begin{array}{c}\text { Descending } \\
\text { VV }\end{array}$ & \\
\hline $\begin{array}{c}\text { Perp. } \\
\text { Baseline (m) }\end{array}$ & 466.04 & 52.43 & 41.49 \\
\hline $\begin{array}{c}\text { Temp. } \\
\text { Baseline } \\
\text { (days) }\end{array}$ & 4 & 84.2017 \\
\hline $\begin{array}{c}\text { Height of } \\
\text { Ambiguity } \\
\text { (m) }\end{array}$ & 13.88 & 123.41 & 440 \\
\hline $\begin{array}{c}\text { Doppler } \\
\text { Difference } \\
\text { (Hz) }\end{array}$ & 485.49 & 337.58 & 37.85 \\
\hline
\end{tabular}



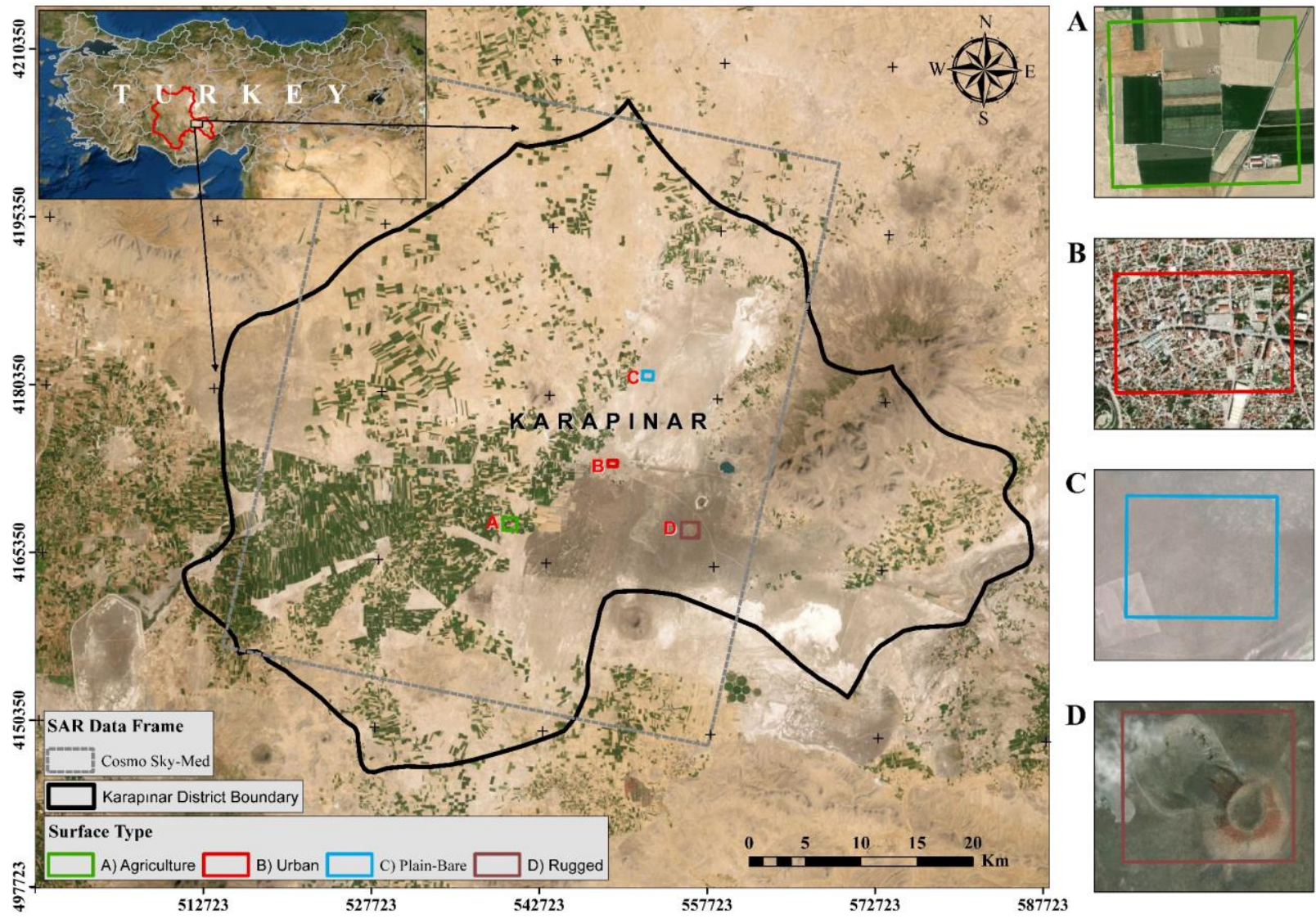

Figure 1. Study areas, A) Agriculture B) Urban C) Plain-Bare D)Rugged.

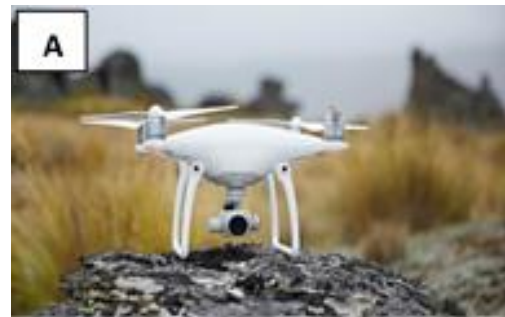

Figure 2. A) UAV b) GCP

\section{METHODS}

Digital Elevation Model (DEM) generation method with InSAR technique was used in the study. As known, InSAR is a radar imaging technique mostly used in remote sensing and geodetic studies (Abdikan, 2007). InSAR technique is based on combining images obtained with radar systems for studies such as DEM generation, deformation measurements and glacier studies (Hanssen, 2001). This technique involve information calculated by acquiring the phase difference of the appropriate image points in each of the two SAR images. The phase difference can be thought of as the value of the temporal difference, in terms of angle, between signals sent to the same location and having the same frequency (Yllmaztürk, 2015).

Digital Elevation Model (DEM) is defined as a data set that presents the elevation information and characteristics of the topography in 3 dimensions (Sefercik, 2007). DEMs can be used as a base for many analyzes that require elevation information in the field of earth sciences. DEMs, can be produced by techniques such as ground survey, aerial photogrammetry, remote sensing, laser scanning and InSAR (Amans et al. 2013; Algancl et al., 2018).

DEM generation with the InSAR technique is based on the process of superimposing, one of the two images of the same region taken at different times as the master image and the other as the slave image (Kyaruzi, 2005). DEM generation process from radar images consists of coregistration, inteferogram generation, phase filtering, phase unwrapping, conversion of phase information to height information and geometric correction stages, respectively (Crosetto ve Crippa, 2000). Figure 3 provides DEM generation stages with InSAR technique.

Coregistration is one of the main steps in interferometric image processing. For this process to occur, at least two SAR images must have similar acquisition geometries. The slave image must match the main image (Gens, 1998; Sefercik, 2010). In the image registration step, operations are carried out under three main headings as stack, cross- correlation and warp. The stack operator is the geographic resampling of two images (master and slave) that are generated by repeated scanning of the same region. Meanwhile, the values of the slave image are resampled according to the master image. The cross-correlation process step is the alignment of the same point on the earth that matches the master image. The warp operator that working with the cross-correlation, performs a mathematical calculation using GCPs automatically generated by the software for matching. 


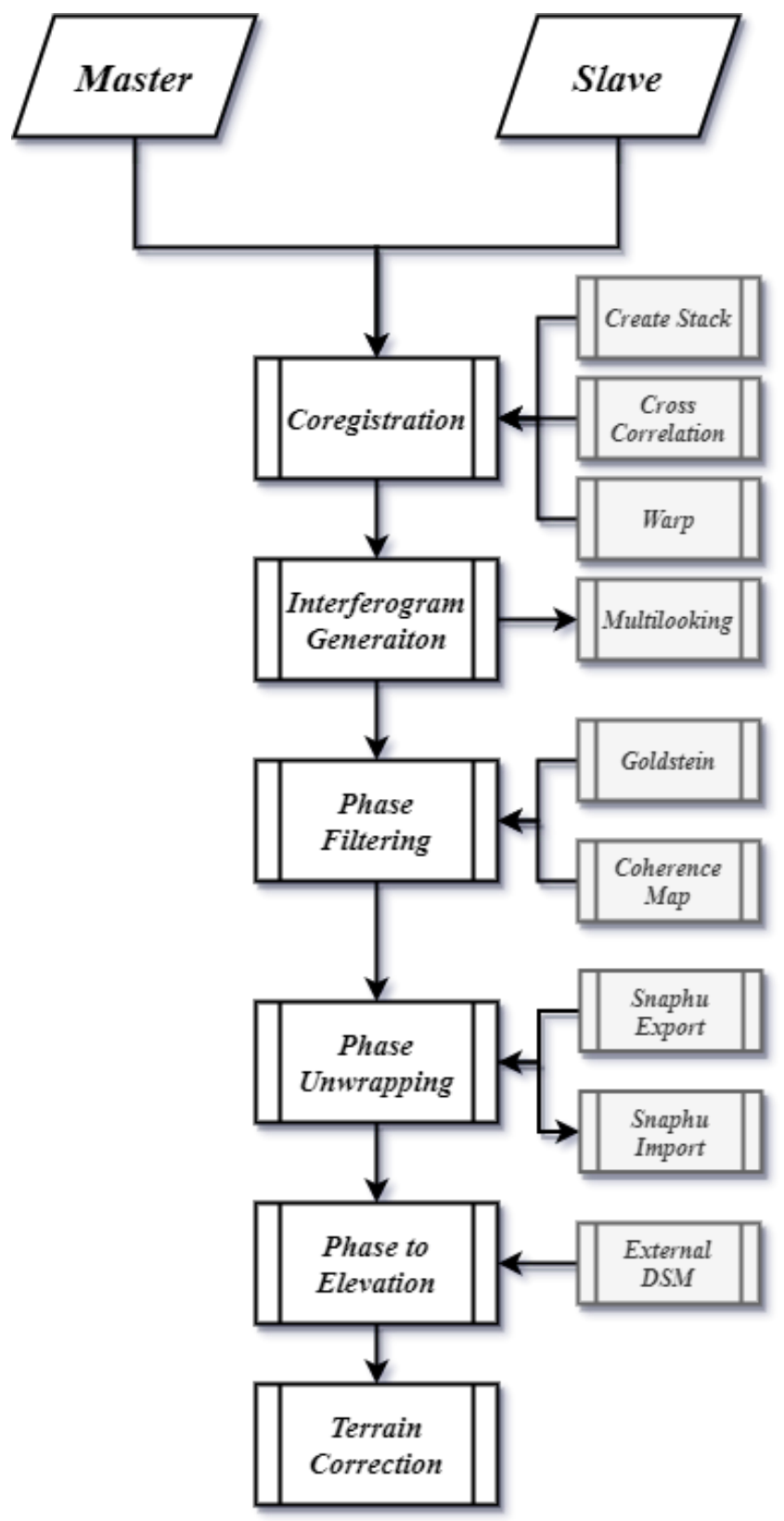

Figure 3. InSAR DEM generation flowchart

Interferograms are images obtained from two different SAR images of the same region and that contain the phase difference information between these two images (Richards, 2009). With the interferogram generation step, a more useful single image is generated by using the InSAR pair. The amplitudes of the corresponding pixels in both images are averaged and the difference of the phase values for each point in the image is calculated. The new image obtained after all these processes is called as interferogram.

Filtering is a process performed to increase the signal to noise ratio to increase the quality of the interferogram. The filter softens the spectrum of the interferogram into small pieces, using the amplitude values of the spectrum. In this process, the noise in the image is assumed to be lower than the other signals and suppressed and large amplitudes are enriched by assuming that the actual signal in the spectrum has a relatively large amplitude (Şengün, 2009). The most widely used filter in the literature is the adaptive phase filtering developed by Goldstein and Werner (Şengün, 2009; Song et al., 2014).

The interferogram showing the height differences of the topography is the module of $2 \pi$. The interferogram contains uncertainty in its content. To obtain height information at each point in the image, the correct integer number of phase cycles must be added to each measurement. The process of removing this uncertainty is called phase unwrapping.

Elevation information obtained from InSAR data is calculated with satellite orbit parameters and specific satellite geometry. Satellite orbit parameters are produced in The Earth Centered Earth Fixed (ECEF) coordinate system. This shows that a reference ellipsoid is needed for elevation calculations (Gens, 1998; Sefercik, 2010). For this reason, a reference DEM is used when performing the phase-elevation conversion. Shuttle Radar Topography Mission (SRTM) elevation models were used as the reference DEM for all images in this study.

The geometric correction of SAR images is different from optical images. Since SAR data have a side view geometry, a geometric distortion occurs on the data produced. Since SAR systems cause nonlinear compression, they cannot be corrected using polynomials. A geometric correction should be made by considering the sensor and processor characteristics (Sefercik, 2010). At this stage, the Range-Doppler terrain correction method is used for SAR images. This method assures the correction of geometric distortions caused by factors such as foreshortening and shadow, using a DEM to correct the position of each pixel.

To compare the DEMs produced with the InSAR technique, the reference DEM to be used in the analysis was produced by evaluating the determined areas with photogrammetric methods with an UAV. At this stage, unique flight plans were prepared for each region, with $100 \mathrm{~m}$ flight altitude and $80 \%$ longitudinal overlap (Figure 4). Also, 20 GCPs were used for each pilot area and 10 of them were reserved for testing the model produced.

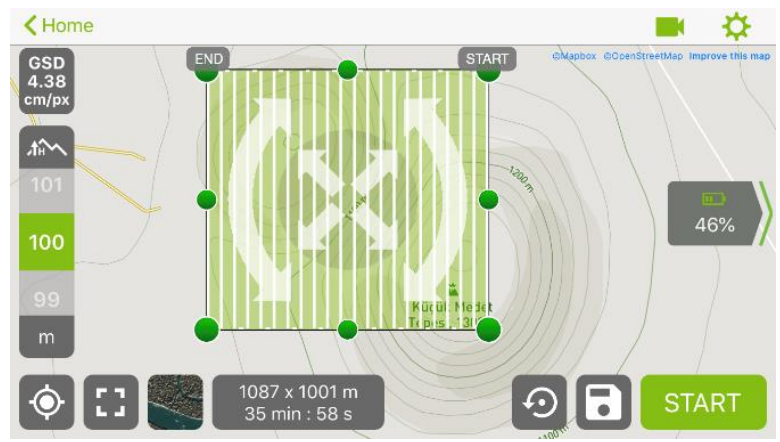

Figure 4. Flight plan sample

As a result of the photogrammetric evaluation of the photographs, 3D model of the land surface and orthomosaic image can be obtained. During these processes, all photographs are evaluated using the coordinates of the GCPs established on the land surface as a reference. The produced data and GCPs were analyzed via Pix $4 \mathrm{~d}$ software. At the end of the process DEMs produced which have $\pm 10 \mathrm{~cm}$ precision. DEM 
obtained at this stage of the study was used as a reference for the evaluation of DEMs produced from InSAR data.

\subsection{Statistical Analysis}

Statistical analyzes were made to evaluate the DEMs obtained in the study. Root Mean Square Error (RMSE), Relative Root Mean Square Error (R-RMSE), Normalized Root Mean Square Error (N-RMSE) and Mean Absolute Error (MAE) analyzes were performed, respectively.

RMSE is the most suitable evaluation method for DEM data (Yang and Hodler, 2000). MAE calculates the mean errors independent of the directions of the variables. In order to obtain the total error, the differences of reference and observation data should be summed and divided by the number of observations (Güvenç, 2020).

RMSE, R-RMSE, N-RMSE and MAE calculated by following equations (Eq. 1-4) respectively.

$$
\begin{gathered}
R M S E=\sqrt{\sum_{i=1}^{n} \frac{\left(Z_{r}-Z_{o}\right)^{2}}{n}} \\
R-R M S E=\sqrt{\sum_{1}^{n} \frac{1}{n}\left(\frac{Z_{r}-Z_{o}}{Z_{o}}\right)^{2}} \\
N-R M S E=R M S E / Z_{r} \\
M A E=\frac{\sum_{1}^{n}\left(Z_{r}-Z_{o}\right)}{n}
\end{gathered}
$$

where $\mathrm{Z}_{\mathrm{r}}$ is the elevation values of reference $\mathrm{DEM}, \mathrm{Z}_{\mathrm{o}}$ is the elevation values of observed DEM and $n$ is the number of observations.

\subsection{DEM Evaluation}

Several processes have been applied to compare the produced DEMs with the reference DEM. Due to the coordinate systems and datum effects of the produced DEMs, there may be problems of not fully overlapping with each other on the horizontal. In order to eliminate this issue DEMSHIFT module of BLUH software developed by Dr. Karsten Jacobsen, Institute of Photogrammetry and Geoinformation (IPI), University of Hannover, Germany was used. The module can eliminate the horizontal position errors of the produced DEMs according to the reference DEM depending on the slopes of the land. Figure 5 shows the effect of horizontal position error on vertical accuracies. The error of $\Delta D$ of the $\mathrm{X}$ point given in Figure 5 was detected and corrected in the $\mathrm{X}$ and $\mathrm{Y}$ directions, and the overlapping of the data was achieved. As a result of this process, the height error of $\Delta \mathrm{Z}$ is eliminated.

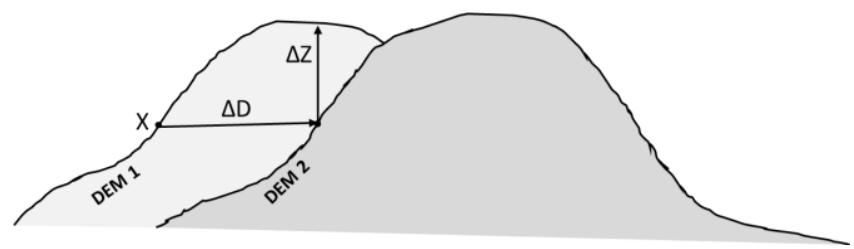

Figure 5. The effect of $\mathrm{X}-\mathrm{Y}$ axis error on $\mathrm{Z}$ axis error (Adapted from Sefercik, 2018)

\section{RESULTS and DISCUSSIONS}

In the study, we compared short, medium and longbaseline data produced by interferometric methods and DEMs produced by UAVs and performed the statistical analysis. First of all, horizontal position errors of DEMs produced by interferometric methods were corrected by reference DEM by using the DEMSHIFT module (Jacobsen, 2005). Table 2 represents the applied corrections in $\mathrm{X}$ and $\mathrm{Y}$ directions according to the study areas. Figure 6 shows DEMs produced with InSAR data and UAV

Table 2. Horizontal shifting values of DEMs according to land surface types (LST)

\begin{tabular}{|l|l|l|l|l|l|l|}
\hline \multirow{2}{*}{ LST } & \multicolumn{2}{|c|}{ Short } & \multicolumn{2}{c|}{ Medium } & \multicolumn{2}{c|}{ Long } \\
\cline { 2 - 7 } & $\mathrm{X}(\mathrm{m})$ & $\mathrm{Y}(\mathrm{m})$ & $\mathrm{X}(\mathrm{m})$ & $\mathrm{Y}(\mathrm{m})$ & $\mathrm{X}(\mathrm{m})$ & $\mathrm{Y}(\mathrm{m})$ \\
\hline Plain-Bare & 0.125 & -2.852 & 0.149 & -2.365 & -0.834 & 2.279 \\
\hline Rugged & 1.052 & 5.704 & -1.097 & -5.363 & -1.535 & -2.698 \\
\hline Urban & -0.294 & 2.689 & -0.304 & -2.700 & -0.300 & -2.691 \\
\hline Agriculture & 1.373 & 4.829 & 1.383 & -4.835 & 1.153 & -4.867 \\
\hline
\end{tabular}

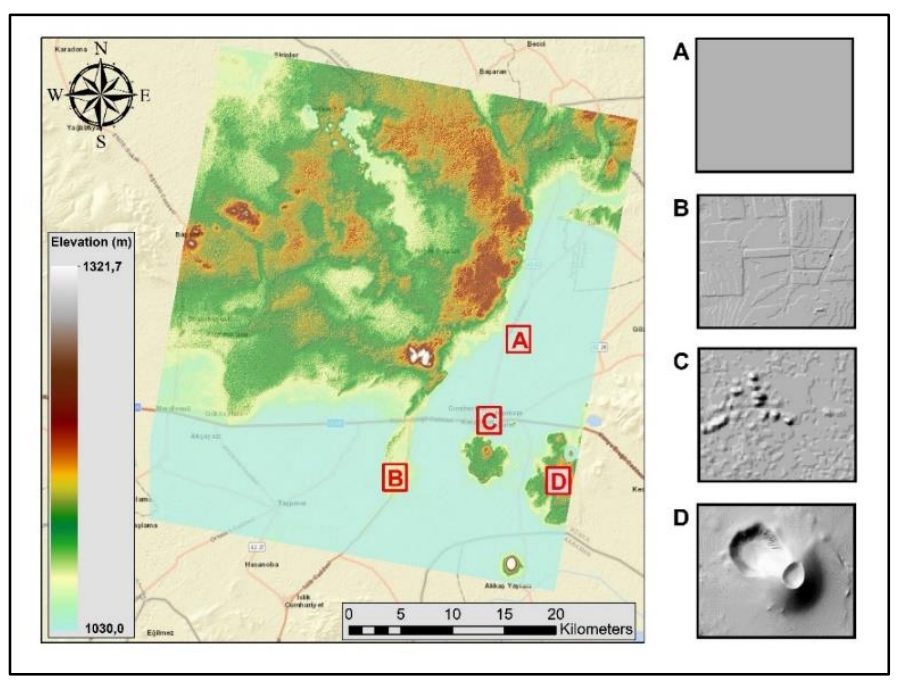

Figure 6. Produced DEMs with InSAR and UAV A) UAV Plain-Bare Area, B) UAV Agricultural Area, C) UAV Urban Area, D) UAV Rugged Area 

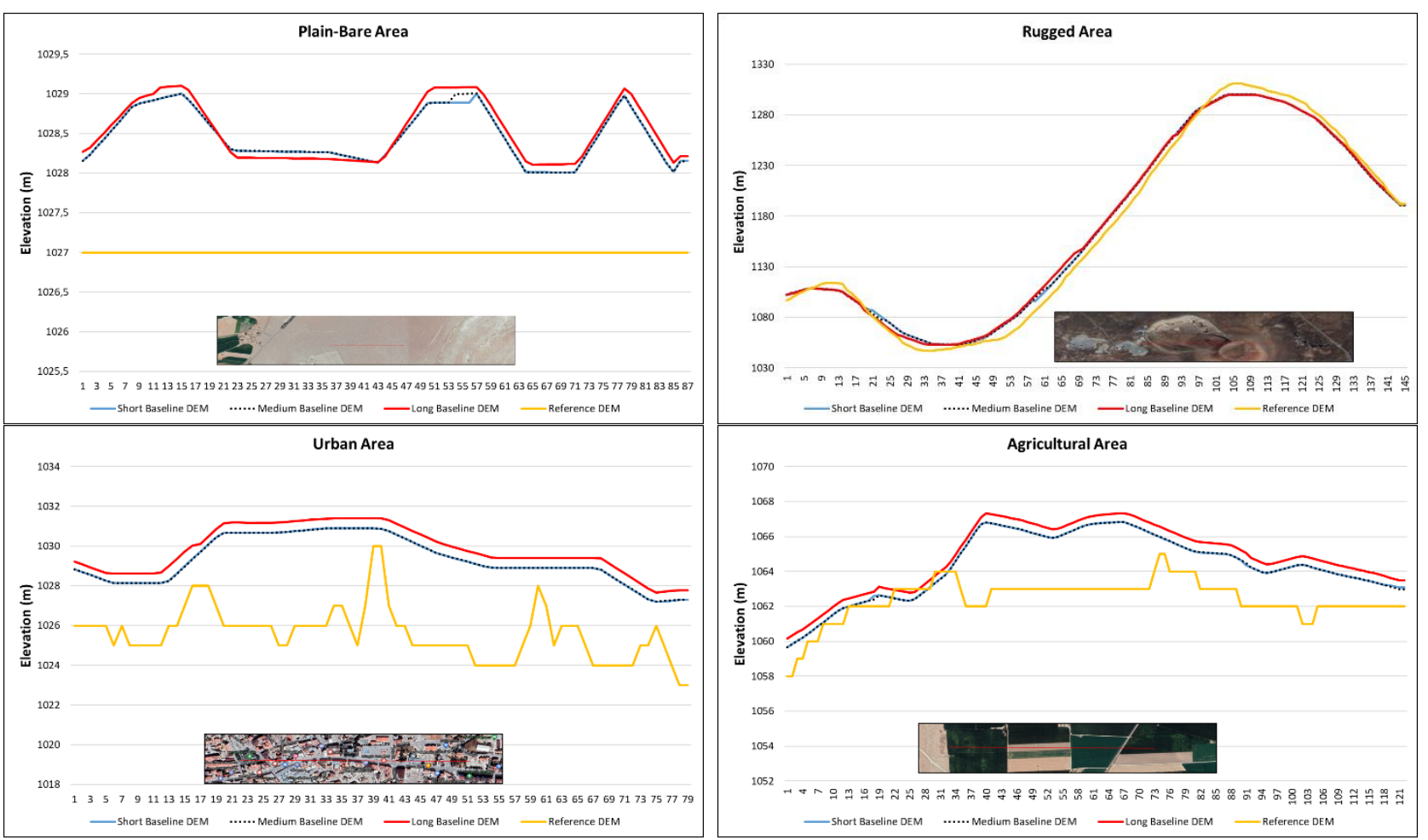

Figure 7. Profile plots according to land surface type

Profile graphics according to different land surface types are displayed in Figure 7. Profiles were extracted using the values taken from areas determined from different land surface types. When the profile charts are examined, it is clearly understood that InSAR data are affected by land surface types.
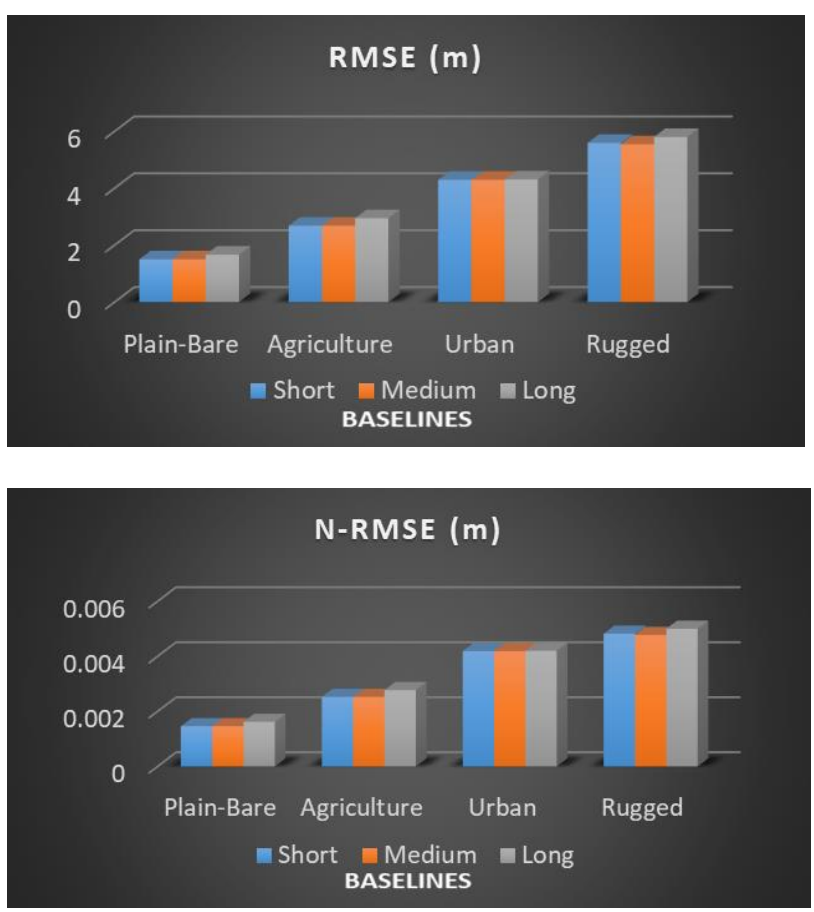

Figure 8. Statistical analysis results

The statistical analysis charts shown in Figure 8 were created using an average of 10000 control points for all areas. Statistical analyses have been calculated based on the reference DEM produced by UAV. In RMSE evaluations, it can be said that short baseline DEM
On the other hand, generally, while short and medium baseline data indicate close values in all graphs, there are differences in data with long baseline. This situation is seen in the sections taken from the profile graphs.

Statistical analysis graphics applied to the data are shown in Figure 8.
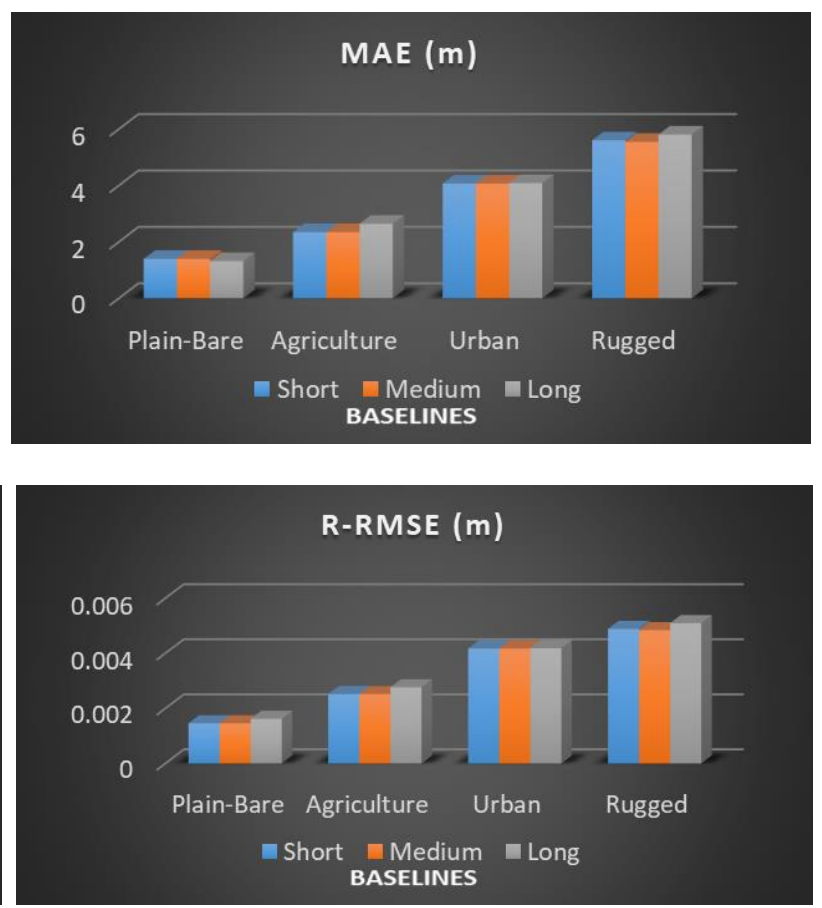

(4days) generally has the smallest RMSE value compared to other DEMs. It has $1.5 \mathrm{~m}$ for the plain-bare area, $2.7 \mathrm{~m}$ for the agricultural area, $4.3 \mathrm{~m}$ for urban area and $5.6 \mathrm{~m}$ for the rugged area, RMSE value respectively. Also, it showed similar results in MAE values (1.4 m-2.3 m-4.1 
m-5.6 m respectively). As well, R-RMSE and N-RMSE values gave similar results too. Considering the medium baseline DEM (84 days) data, it can be seen that there are no large deviations from the short baseline data. As shown in Figure 8, while better results are obtained for plain-bare areas in RMSE values, the error occurring in other areas increases. It is possible to observe these results in other statistical analyzes. Also, when the analysis results of long baseline DEM were examined, it was observed that there were apparent differences from other produced DEMs. RMSE values have reached $1.8 \mathrm{~m}$ for long baseline plain-bare area, $3 \mathrm{~m}$ for agricultural area, $4.3 \mathrm{~m}$ for urban area and $5.8 \mathrm{~m}$ for rugged area. In other analyzes, the differences of long baseline data appeared similarly.

The $1.5 \mathrm{~m}$ RMSE value obtained in the Plain-Bare area highlights an important point about the accuracy of the DEMs obtained. Also, when the produced DEMs are examined holistically, it is revealed that the average RMSE values are approximately $3.5 \mathrm{~m}$. This shows that the absolute vertical error of the produced DEMs are better than the RMSE values of TSX-WorldDEM which is about $4 \mathrm{~m}$ (Airbus, 2018), SRTM DEM is $10 \mathrm{~m}$ (Farr et al., 2007), ALOS World3D DEM is about $5 \mathrm{~m}$ (Tadono et al., 2014) and ASTER GDEM V2 is about $9 \mathrm{~m}$ (Tachikawa et. al., 2011).

In this study, the effect of land surface types on accuracies was revealed more clearly because the baseline was not compared in a single land surface type. When the Figure 8 were examined, despite the elevation changes in plain-bare and agricultural land were not very different the RMSE values of the agricultural lands were higher than the plain areas. The noise effect of agricultural areas on InSAR data is reflected in the results in this way. At the same time, the buildings and urbanization factors that affect the DEM data caused deviations in the data of the urban areas. In addition, the rugged area data has the highest error value can be explained by the effects that occur during image acquisition (layover, shadow, foreshortening) in the radar data. Errors caused by the land surface during image acquisition also affect the result products produced with InSAR data.

\section{CONCLUSION}

In this study, DEMs produced from short, medium and long baseline data of COSMO Sky-Med satellite were compared with DEM produced by UAV. Profile graphics were drawn from the produced data and statistical analysis was performed on the data.

It is understood from all the analysis that long baseline data have larger deviations than short and medium baseline data. This is due to climate change, seasonal conditions and similar factors as well as errors that occur during the processing of InSAR pairs. It is obvious that not all land surface types will be the same. Therefore, the emergence of different results in different land surface types also creates a drawback in the use of long baseline data. The authors recommend that scientists avoid using long baseline data in DEM generation and deformation studies, where the results should be sensitive.
The fact that the comparisons made with the baseline of the COSMO Sky-Med satellite are limited in the literature makes this study unique. The results can be evaluated by diversifying the baselines and making different analyzes in future studies.

\section{REFERENCES}

Abdikan S (2007). SAR Görüntülerinden Üretilen İnterferometik Ve Stereo Sayısal Yükseklik Modellerinin Kalitesinin İncelenmesi. Master Thesis, Yldız Technical University, Graduate School of Science and Engineering, Turkey.

Airbus (2018). WorldDEM ${ }^{\mathrm{TM}}$ Technical Product Specification, Airbus Defence and Space Intelligence.

Alganci U, Besol B \& Sertel E (2018). Accuracy assessment of different digital surface models. ISPRS International Journal of Geo-Information, 7(3), 114.

Amans O C, Beiping W \& Ziggah Y Y (2013). Assessing Vertical Accuracy of SRTM Ver. 4.1 and ASTER GDEM Ver. 2 using Differential GPS Measurements-case study in Ondo State, Nigeria. International Journal of Scientific and Engineering Research, 4(12), 523-531.

Bamler R \& Hartl P (1998). Synthetic aperture radar interferometry. Inverse Probl, 14: R1-R54 .

Bishop M P, Bonk R, Kamp Jr U \& Shroder Jr J F (2001). Terrain analysis and data modeling for alpine glacier mapping. Polar Geography, 25(3), 182-201.

Covello F, Battazza F, Coletta A, Lopinto E, Fiorentino C, Pietranera L, Valentini \& Zoffoli S (2010). COSMOSkyMed an existing opportunity for observing the Earth. Journal of Geodynamics, 49(3-4), 171-180.

Crosetto M \& Crippa B (2000). Quality assessment of interferometric SAR DEMs. International Archives of Photogrammetry and Remote Sensing, 33(B1; PART 1), 46-53.

Erasmi S, Rosenbauer R, Buchbach R, Busche T \& Rutishauser S (2014). Evaluating the quality and accuracy of TanDEM-X digital elevation models at archaeological sites in the Cilician Plain, Turkey. Remote sensing, 6(10), 9475-9493.

Erten E, Çelik M F \& Şahin Z M (2018). TanDEM-X Digital Elevation Model Generation- TANDEM-X SayısalYükseklik Modelinin Oluşturulması. Harita Dergisi, 84(160), 47-54.

Farr T G, Rosen P A, Caro E, Crippen R, Duren R, Hensley S, Kobrick M, Paller M, Rodriguez E, Roth L, Seal D, Shaffer S, Shimada J, Umland J, Werner M, Oskin M, Burbank D \& Alsdorf D (2007). The shuttle radar topography mission. Reviews of geophysics, 45(2).

Gao X, Liu Y, Li T \& Wu D (2017). High Precision DEM Generation Algorithm Based on InSAR Multi-Look Iteration, Remote Sensing, 9, 741Tracking. Turkish Journal of Geosciences, 1(1), 1-7.

Gens R (1998). Quality Assessment of SAR Interferometric Data, Ph.D Thesis, Hannover, ISSN 01741454

Güvenç M (2020) Comparatıve evaluatıon of vertıcal accuracy of ground control points from ASTER-DEM SRTM-DEM with respect to ALOS-DEM. M.Sc. Thesis. Hasan Kalyoncu University Graduate School of Natural and Applied Sciences. 
Hageman J B, Bennett D A, Westcott K L \& Brandon R J (2000). Construction of digital elevation models for archaeological applications. Practical Applications of GIS for Archaeologists: A Predictive Modelling Toolkit, 121-136.

Hanssen R F (2001). Radar interferometry: data interpretation and error analysis (Vol. 2). Springer Science \& Business Media.

Hengl T \& Evans I S (2009). Mathematical and digital models of the land surface. Developments in soil science, 33, 31-63.

Jacobsen K (2005). DEMs based on space images versus SRTM height models. In ASPRS annual convention Baltimore.

Karabörk H, Makineci H B, Orhan O \& Karakus P (2021). Accuracy Assessment of DEMs Derived from Multiple SAR Data Using the InSAR Technique. Arabian Journal for Science and Engineering. https://doi.org/10.1007/s13369-020-05128-8

Kyaruzi J (2005). Quality Assessment of DEM from Radargrammetry Data. M.sc Thesis, International Institute for Geo-information Science and Earth Observation, Enschede, The Netherlandsz.

Martha T R, Kerle N, Jetten V, van Westen C J \& Kumar K V (2010). Characterising spectral, spatial and morphometric properties of landslides for semiautomatic detection using object-oriented methods. Geomorphology, 116(1-2), 24-36.

Miller C L \& Laflamme R A (1958). The Digital Terrain Model-: Theory \& Application. MIT Photogrammetry Laboratory.

Orhan O, Kırtıloğlu O S \& Yakar M (2020a). Konya Kapalı Havzası Obruk Envanter Bilgi Sisteminin Olușturulması. Geomatik, 5(1), 92-104.

Orhan 0, Yakar M \& Ekercin S (2020b). An application on sinkhole susceptibility mapping by integrating remote sensing and geographic information systems. Arabian Journal of Geosciences, 13(17), 1-17.

Peralvo M \& Maidment D (2004). Influence of DEM interpolation methods in drainage analysis. Gis Hydro, 4.

Pope A, Murray T \& Luckman A (2007). DEM quality assessment for quantification of glacier surface change. Annals of Glaciology, 46, 189-194.

Richards J A (2009). Remote sensing with imaging radar (Vol. 1). Berlin: Springer.

Sefercik U (2018). Zamansal Baz Uzunluğunun İleri Nesil Yapay Açıklı Radar Uydu Verilerinin Konum Doğruluğu Üzerindeki Etki Analizi . Çukurova Üniversitesi Mühendislik-Mimarlık Fakültesi Dergisi , 33 (2) , 165-176 . DOI: 10.21605/cukurovaummfd.509184

Sefercik U G (2007). Comparison of DEM accuracies generated by various methods. In 2007 3rd
International Conference on Recent Advances in Space Technologies (pp. 379-382). IEEE.

Sefercik U G (2010). Generation And Evaluation Of DEMs Derived By TERRASAR-X Insar Images. PhD diss., Zonguldak Karaelmas University, Graduate School of Science and Engineering, Turkey.

Sefercik U G, Buyuksalih G \& Atalay C (2020). DSM generation with bistatic TanDEM-X InSAR pairs and quality validation in inclined topographies and various land cover classes. Arabian Journal of Geosciences, 13(13), 1-15.

Șengün Y S (2009). GPS ve Insar ölçülerini birlikte kullanarak İzmit depreminde oluşan deformasyonların belirlenmesi: Nokta seyrekleştirmede yeni bir algoritma. PhD Thesis, Istanbul Technical University, Graduate School of Science Engineering and Technology.

Song R, Guo H, Liu G, Perski Z, Yue H, Han C \& Fan J (2014). Improved Goldstein SAR interferogram filter based on adaptive-neighborhood technique. IEEE Geoscience and Remote Sensing Letters, 12(1), 140144. doi: 10.1109/LGRS.2014.2329498.

Szypuła B (2017). Digital elevation models in geomorphology. Hydro-Geomorphology-Models and Trends. InTechOpen, 2017b, 81-112.

Tachikawa T, Kaku M, Iwasaki A, Gesch D B, Oimoen M J, Zhang Z, Denielson J, Krieger T, Curtis B, Haase J, Abrams M, Crippen R \& Carabajal C (2011). ASTER global digital elevation model version 2-summary of validation results. NASA.

Tadono $\mathrm{T}$, Ishida $\mathrm{H}$, Oda $\mathrm{F}$, Naito $\mathrm{S}$, Minakawa $\mathrm{K}$ \& Iwamoto H (2014). Precise global DEM generation by ALOS PRISM. ISPRS Annals of the Photogrammetry, Remote Sensing and Spatial Information Sciences, 2(4), 71.

Yang X \& Hodler T (2000). Visual and statistical comparisons of surface modeling techniques for point-based environmental data, Cartography and Geographic Information Science, 27(2):165-175.

Yang K, Smith L C, Chu V W, Gleason C J \& Li M (2015). A caution on the use of surface digital elevation models to simulate supraglacial hydrology of the Greenland ice sheet. IEEE Journal of Selected Topics in Applied Earth Observations and Remote Sensing, 8(11), 52125224.

Yılmaztürk S (2015). Sbas-ınsar Yöntemiyle Düşey Yönlü Yüzey Deformasyonlarının Belirlenmesi: Bursaorhaneli Linyit Madeni Örneği. Master Thesis, İstanbul Technical University, Institute of Science and Technology, Turkey.

Zebker H A, Goldstein R M (1986). Topographic mapping from interferometric SAR observations, J Geophys Res, 91:4493-4999. 